\title{
FIGAL, Günter. Nietzsche: uma introdução filosófica. Trad. Marco Antônio Casanova. Rio de Janeiro: Mauad X, 2012.
}

* Roberto Saraiva Kahlmeyer-Mertens

$\mathrm{E}$ m fins de 2012, foi editada a tradução de Nietzsche: uma introdução filosófica, de Günter Figal (Mauad X, 2012). Conhecida do público europeu desde a década de 1990, esta obra de fôlego, a contar dessa data, vem contribuindo com a elevação do nível das pesquisas sobre Nietzsche no exterior. Fenômeno que talvez se explique pela visada peculiar que seu autor joga sobre a filosofia de Nietzsche.

Embora apontado como um dos principais representantes da Nietzsche Forchung alemã (ao lado de Günter Abel e Volker Gehardt), Günter Figal não seria um leitor de Nietzsche no sentido estrito do termo. Formado no caldo de cultura da fenomenologia-hermenêutica, tendo sido aluno de Hans-Georg Gadamer e herdeiro direto da filosofia de Martin Heidegger (a ponto de, atualmente, ocupar a cátedra que pertencera ao filósofo na Universidade Albert-Ludwig, em Freiburg), é inevitável encontrar na interpretação que Figal faz de Nietzsche traços influentes de sua formação.

Muito mais do que exegese do texto nietzschiano, o livro deixa transparecer o esforço de partir da obra do filósofo, e das interpretações estabelecidas na fortuna crítica, para uma aproximação gradual do horizonte significativo do pensamento de Nietzsche. Assim, ao arrancar das posições, visões e conceptualizações que as leituras disponíveis oferecem-nos, Günter Figal reconstrói o cenário no qual o pensamento de Nietzsche fez-se possível, passa em revista crítica as teses consolidadas sobre tal filosofia e, por fim, descreve o que se evidencia a partir de um

* Doutor em Filosofia pela Universidade do Estado do Rio de Janeiro - UERJ. Professor Adjunto na Universidade Estadual do Oeste do Paraná-UNIOESTE. <kahlmeyermertens@gmail.com>. 
Nietzsche livre dos cacoetes de algumas interpretações tradicionais. A tríade reconstrução, revisão crítica e reinterpretação (que delineia o itinerário do livro de Figal) será a mesma que oferecerá estruturação a esta resenha.

O gesto reconstrucionista é particularmente identificado no capítulo inicial. Dividido em três tópicos, no primeiro, intitulado "Sismógrafo", o autor oferece-nos um verdadeiro inventário da recepção da obra de Nietzsche na contemporaneidade. É digno de nota que tal balanço não se restringe à cena filosófica. Figal indica como o pensamento de Nietzsche infiltrou-se nas ciências humanas e sociais por meio de Georg Simmel e de Max Weber; como os influxos das ideias estéticas do filósofo serviram de inspiração a músicos como Gustav Mahler e Richard Strauss; como o espírito da obra nietzschiana passou à literatura dos irmãos Mann (Heinrich e Thomas), de Gottfried Benn e, em especial, de Ernst Jünger. Valendo-se desta contextualização, Günter Figal indica, a partir deste último, o papel que Nietzsche desempenhara em seu tempo. Em uma época de crise, na qual a filosofia ainda se ressentia da ruína dos idealismos (para os quais Hegel e os hegelianos representavam uma espécie de aristocracia metafísica) e da ascensão bárbara do positivismo, a lucidez de Nietzsche não seria um terremoto, mas o sensor que descreve e interpreta tais abalos, ou, nas palavras de Jünger:

Ele investiga os caminhos possíveis, as rotas mais extremas sobre as quais a razão fracassará. A apreensão intelectual da catástrofe é mais terrível do que os medos reais do mundo do fogo. (...) Partir-se assim era o destino de Nietzsche: hoje é de bom tom apedrejá-lo. Do mesmo modo que depois do terremoto, as pessoas se abatem sobre o sismógrafo. Não obstante, não se pode fazer que o barômetro expie a culpa pelo furacão se não se quiser adentrar as fileiras dos primitivos. ${ }^{1}$

A metáfora do sismógrafo como indicativa do posto de Nietzsche é apenas uma das muitas tiradas felizes do ensaio de Figal neste momento propedêutico. Os tópicos que se seguem a este (a saber, "Biografia" e "Definições de posição") reforçam pontos ali esboçados.

Sem a erudição histórica das biografias disponíveis no mercado e com uma condução que nos lembra, em certos lances, os parágrafos biográficos do primeiro volume das preleções de Heidegger sobre Nietzsche, a obra de Figal oferece-nos uma narrativa da vida e obra deste pensador. Do mesmo modo que Andler, ${ }^{2}$ Figal valoriza a juventude de Nietzsche: seu período de formação filológica na Escola de Pforta,

JÜNGER apud FIGAL, 2012.

2 ANDLER, 1921. 
seu convívio amistoso com o mestre filólogo F. W. Ritschl, o desgosto da carreira docente, a amizade malograda com R. Wagner, a maturação das ideias mais tenras da infância em $A$ origem da tragédia e os primeiros fustigos por parte do seu ex-condiscípulo U. v. Wilamovitz-Moellendorff (o filólogo).

Deste bosquejo biográfico, entretanto, o que mais importa é a indicação de que Nietzsche, voluntariamente afastado da universidade e possuindo reduzido um círculo de amizades, volta-se para si tornandose pela primeira vez presente como pensador por meio de sua escrita. Figal sustenta a tese de que, para Nietzsche, e ao contrário dos demais filósofos, "(...) o que está em questão para ele não é nem mesmo um programa filosófico que pudesse subsistir por si e seria designado por meio de seu nome (...). Nietzsche se retrai ante o desenvolvimento das ideias que poderiam ser aplicadas sem uma consideração da pessoa."3 Caracteriza-se, assim, a concepção nietzschiana da "vida como literatura".

Os pontos de partida para a elaboração do que seria uma escrita de si e um si mesmo como filosofia é o que se encontrará no já mencionado tópico "Definições de posição". É aí que o comentador (após a revisão literária das interpretações de Nietzsche que fizeram escola: Jaspers, Heidegger, Lukács, Adorno e Derrida) aponta o lugar que o filósofo de Röcken ocupa na história da filosofia: “(...) Nietzsche não pode mais ser pensado agora meramente em contraste com a tradição; se Nietzsche é o filósofo moderno por excelência e ao mesmo tempo pertence à metafísica, isso é uma prova do caráter metafísico da modernidade (...)"4

Tal afirmação causaria certamente desconforto aos acostumados a conceber Nietzsche como o arauto do pensamento não metafísico, convicto opositor da tradição. Entretanto, bem como Heidegger, Figal entende que Niezsche ainda possui ligação com a tradição filosófica justamente por depender de pressupostos e arrolar consequências de ideias e condutas próximas à metafísica.

É nesse momento que a principal tese do livro aparece, tal tese alinha a conduta de Nietzsche à figura paradigmática do Sócrates e liga seu pensamento a Platão. Em que sentido? Resposta: primeiramente, ao contar com a tradição de pensamento ocidental para colocar-se em diálogo com conceitos e questões filosóficas; depois, por sua filosofia tornar-se o que é na medida em que se diferencia da tradição, fazendo desta um outro de si, isto é: na maneira pouco canônica com a qual Nietzsche contempla o mundo e confronta-se com a metafísica, a tradição filosófica experimenta sua alteridade. Mas, para Figal, ainda que a 
filosofia de Nietzsche desconstrua as bases da metafísica e proponhase em termos diversos da tradição (Figal não insinua que Nietzsche reproduza Platão), mesmo o "filosofar a marteladas" guardaria vestígios de sua natividade metafísica. Diante do caráter polêmico desta tese, o resumo pálido que esta resenha apresenta (coerentemente a sua proposta de recensão e adequando-se ao espaço que lhe é cabido), não permite que o leitor prescinda da leitura deste terceiro tópico do primeiro capítulo, bem como os diversos momentos adiantados do texto no qual a premissa ganha desdobramentos. É possível, entretanto, concordar com o comentador quanto a seu esforço por caracterizar de maneira mais rigorosa e uniforme a figura filosófica de Nietzsche, descerrar um filósofo "mais estranho, mais espantoso e mais conhecido ao mesmo tempo". 5

A transição do Capítulo primeiro aos próximos deixa transparecer, novamente, uma atitude hermenêutica. Denominado De fora, o primeiro momento apresentava as circunstâncias externas a partir das quais ingressaríamos na leitura da obra em busca de uma compreensão do pensamento de Nietzsche. Destarte, partindo das compreensões prévias que a narrativa biográfica e as interpretações autorizadas oferecem, pode ter início o caminho de intensificação de compreensões da obraNietzsche. É isso que se encontra no capítulo segundo, intitulado Tempo, ser e devir. O referido nome explica-se pelos tópicos encontrados nesta seção.

Em tais pontos encontramos a tematização de noções-chave do pensamento de Nietzsche, como o devir, força plástica e arte, apresentadas por meio de citações do autor de Assim falou Zaratustra. A qualificação de Figal enquanto intérprete de Nietzsche evidencia-se desde que nos deparamos com as passagens que o autor escolhe para tematizar (tal seleção, por si só, justifica uma leitura dos tópicos). Num diálogo intrínseco à obra de Nietzsche, e sem fugir ao enfrentamento das leituras mais acatadas, Figal revisa criticamente a maneira com que conceitos, temas e questões decorrentes do pensamento de Nietzsche vêm sendo apropriados. Muito do exercício de interpretação do comentador consiste em desmontar essas interpretações cristalizadas para liberar o interpretado a um horizonte no qual seja favorável a identificação do solo no qual este estaria fundado. Movimento hermenêutico idêntico é o que se repete no terceiro e quarto capítulos.

Aguardado durante toda a leitura, é no último capítulo da obra que o problema do conhecimento aparece. Sob a alcunha de Vida do conhecimento, podemos conferir a distinta interpretação que Figal dedica aos conceitos mais fundamentais do pensamento nietzschiano, ao

5 FIGAL, 2012, p. 13 
exemplo: o super-homem (na peculiar opção de tradução como "além-dohomem"), a vontade de poder, o eterno retorno e a psicologia (conceitos homônimos aos tópicos dignos de nota no referido capítulo). Ao apontar estes conceitos como raios para o eixo que o personagem de Zaratustra constitui, Figal pode elucidar o quanto essas noções dão voz a uma doutrina da vida. Importa, entretanto, ao comentarista indicar o quanto mesmo esta doutrina em sua presumida liberdade de pensamento ainda não teria suas bases no solo tradicional do platonismo, este contra o qual o próprio Nietzsche volta-se. Tal tarefa, que parece perpassar inteiramente Nietzsche, constitui uma introdução filosófica, que se torna mais nítida na terceira porção do trabalho.

Ao longo das 248 páginas que dão corpo à tentativa de tornar compreensível a obra de Nietzsche, o livro de Günter Figal - não seria demais assinalar - possui uma linguagem tão didática quanto plástica. Tais atributos discursivos, mais do que um requinte estético, denotam não só a maturidade do pesquisador perante seu objeto de estudo, quanto a preocupação de fazer jus à prosa filosófica do incontestável estilista que foi Nietzsche.

Publicado originalmente na forma de livro de bolso sob o selo da alemã Reclam, a editora brasileira apresenta o livro com arte e editoração elegantes, reservando-lhe lugar especial no interior da Coleção Sapere Aude, que já possui outros títulos referentes a Nietzsche.

\section{Referências}

ANDLER, Charles. La Jeunesse de Nietzsche - Nietzsche as vie et as pensée. 3. ed. Paris: Rossard, 1921.

FIGAL, Günter. Nietzsche: Uma introdução filosófica. Trad. Marco Antônio Casanova. Rio de Janeiro: Mauad X, 2012.

HEIDEGGER, Martin. Nietzsche I. Trad. Marco Antônio Casanova. Rio de Janeiro: Forense Universitária, 2007.

\section{Endereço postal:}

Universidade Estadual do Oeste do Paraná

Reitoria - Campus Universitário de Toledo

Rua da Faculdade - Jardim La Salle

85903000 Toledo, PR, Brasil

Data de recebimento: 05/02/2014

Data de aceite: 30/03/2014 